\title{
Parathyroid Adenoma in \\ Child: A Case with Unusual \\ Presentation
}

CHHANDA DAS, MADHUMITA MUKHOPADHYAY, PRIYANKA MAITY, BEDABRATA MUKHOPADHYAY

\begin{abstract}
Parathyroid adenoma causing hyperparathyroidism occurs mainly in age groups between 50 to 60 years. It is rare in children. Presentation in Paediatric patients with primary hyperparathyroidism is usually with vague symptoms like anorexia, nausea, vomiting, constipation, irritability, polyuria and polydipsia. Few can present with nephrolithiasis, bone
\end{abstract}

pain, rickets or acute pancreatitis. Here, we are presenting a rare case of a 12 years old female child who presented with chief complaints of recurrent abdominal pain for two months. Various investigations proved it to be a case of primary hyperparathyroidism due to parathyroid adenoma and it was successfully treated with surgery.

\section{CASE REPORT}

A 12 years old girl was presented to our hospital with chief complaints of recurrent abdominal pain for 2 months. Pain was recurrent, colicky, aggravated after taking food, associated with vomiting. Per abdomen examination revealed mild tenderness over the epigastrium and no organomegaly. Her vitals, musculoskeletal system examination, routine blood investigations liver function test, lipid profile, thyroid profile were within normal limits. Her serum amylase and lipase levels were mildly elevated. Clinically and biochemically it was suspected as a case of pancreatitis. CT abdomen revealed only mild diffuse enlargement of pancreas. Her serum calcium level was $14.7 \mathrm{mg} / \mathrm{dl}(\mathrm{N}=8.5-10.5 \mathrm{mg} / \mathrm{dl}$ ), phosphorus level was $2.1 \mathrm{mg} / \mathrm{dl}, 25, \mathrm{OH}$-Vit D3 level was $9.95 \mathrm{ng} / \mathrm{ml}(\mathrm{N}=30 \mathrm{ng} / \mathrm{ml})$, Intact PTH level was $741.0 \mathrm{pg} / \mathrm{m}$ $(\mathrm{N}=10-55 \mathrm{pg} / \mathrm{ml}), 24 \mathrm{hrs}$ urinary $\mathrm{ca}^{2+}$ excretion was $521 \mathrm{mg} /$ $\mathrm{dl}$ and calcium: creatinine ratio was 0.027 . Diagnosis of primary hyperparathyroidism was made.

USG of neck and thyroid showed normal left lobe and isthmus. Right lobe was normal except a small hypo echoic oval shaped mass $(2.1 \mathrm{~cm} \times 0.6 \mathrm{~cm})$ located medially near the lower pole. $X$-ray revealed generalized demineralization. Delayed 99mTc-MIBI image showed delayed washout of the lower pole of the right thyroid lobe [Table/Fig-1]. USG guided FNAC of the mass at lower pole of the right thyroid showed haemorrhagic aspirate, high cellularity, aggregates of cohesive cells with small nuclei, coarse granular chromatin, numerous bare nuclei, pale fragile cytoplasm, absence of colloid and macrophage.

Excision of right inferior parathyroid was done and the specimen was sent to Pathology Department for histopathological examination [Table/Fig-2]. On gross examination a well circumscribed and encapsulated nodular mass measuring $1.8 \mathrm{~cm}$ in diameter and weighing $1.22 \mathrm{gm}$ was noted. Microscopic examination showed a diffuse growth pattern, traversed by delicate blood vessels. Tumor cells were polygonal with lightly eosinophilic clear or oxyphilic cytoplasm [Table/Fig-3,4]. Presence of interspersed large cells with bizarre and hyper chromatic nuclei were noted Histopathologi-

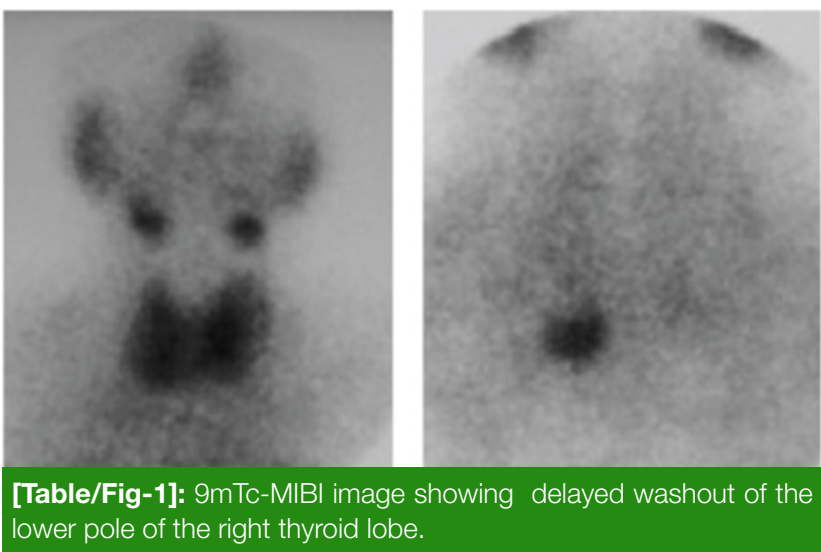



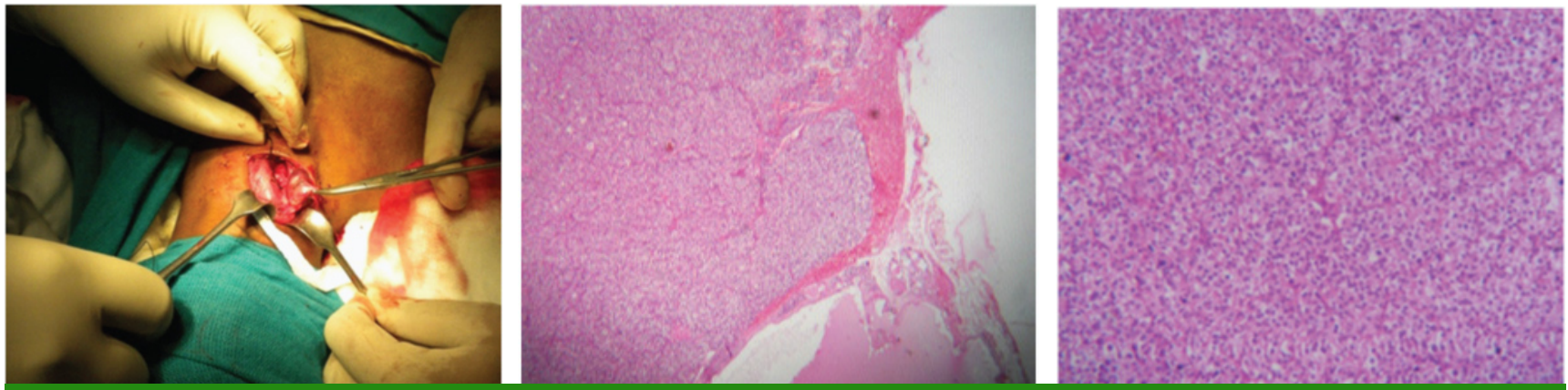

[Table/Fig-2]: Excision of right inferior parathyroid done. [Table/Fig-3]: Mass showing a diffuse growth pattern, traversed by delicate blood vessel (H\&E scanner view). [Table/Fig-4]: Picture showing polygonal tumor cells with lightly eosinophilic, clear or oxyphilic cytoplasm (H\&Ex100).

cal examination of right inferior parathyroid showed features consistent with parathyroid adenoma. Final diagnosis of right inferior parathyroid adenoma with vitamin-D deficiency was made from clinical, biochemical, radiological and histopathological report.

\section{DISCUSSION}

Parathyroid adenoma is a benign encapsulated neoplasm of parathyroid gland usually involving single gland mostly composed of chief cells [1], but mixture of oncocytic cells, transitional oncocytic cells can also be seen. Actual incidence is difficult to determine, according to Mayo Clinic and Europian centres incidence is 17.7 cases per 1,00,000 person/year [2]. Primary hyperparathyroidism due to adenomas occur in all age groups with peak incidence between 50 and 60 years of age with female to male ratio of 3:1.Mostly adenomas involve a single parathyroid gland and the remaining glands are normal. Exceptionally two adenomas may occur [3]. Primary hyperparathyroidism is characterized by hypercalcemia and hypophosphataemia.

Primary hyperparathyroidism occurs in adults and is rare in children [4]. So its diagnosis may be delayed or may be missed in children. It can occur as a component of MEN type I and II Presentation in paediatric patients with primary hyperparathyroidism are usually nonspecific like anorexia, nausea, vomiting, constipation, irritability, polyuria and polydipsia. Nephrolithiasis, bone pain, rickets or acute pancreatitis like symptoms may also occur [5]. In our case age of the patient was 12 years and she presented with abdominal pain and pancreatitis. Pancreatitis is the cause of abdominal pain. Hypercalcaemia activates trypsinogen to trypsin which causes auto digestion of pancreas that leads to pancreatitis. Hypercalcaemia can also lead to pancreatic calculi formation. These calculi obstruct pancreatic ducts and cause pancreatitis. Actual prevalence is difficult to determine, approximately the prevalence of acute pancreatitis in primary hyperparathyroidism is between $1.5 \%$ and $13 \%$ [6]. Early detection of raised serum calcium can help in determining the cause of pancreatitis [6]

In children suspected case of hyperparathyroidism diagnosis can be made by estimation of serum calcium and PTH levels [7]. Imaging modalities like high frequency USG, CT scan and substraction scintigraphy are used for localization of parathyroid mass [8]. Most sensitive and specific for localizing parathyroid adenoma is Technetium99 M-sestamibi scan [9]. Parathyroid resection is treatment of choice for children with primary hyperparathyroidism [10]. After the resection serum calcium level normalizes and child became asymptomatic.

\section{CONCLUSION}

Childhood presentation of prarathyroid adenoma causing primary hyperparathyroidism is rare and pancreatitis is unusual presentation in children. Parathyroid adenomas are well circumscribed and easy to excise. Pancreatitis does not recur once the calcium level normalizes after excision of adenoma.

\section{REFERENCES}

[1] Carney JA: Pathology of hyperparathyroidism: a practical approach. Monogr Pathol. 1993; 35:34-62.

[2] Heath HI, Hodgson SF, Kennedy MA. Primary hyperparathyroidism Incidence, morbidity and potential economic impact in a community. N Engl J Med. 1980 ; 302: 189 -93.

[3] Verdonk CA, Edis AJ. Parathyroid "double adenomas":fact of fiction? Surgery. 1981.90:523-26.

[4] Kollars $\mathrm{J}$ et al. Primary hyperparathyroidism in pediatric patients. Pediatrics. 2005; 115(4):974-80.

[5] Bhadada SKetal. Characteristics of primary hyperparathyroidism in adolescents. J Pediatr Endocrinol Metab. 2008; 21(12): 114753.

[6] Misgan RA, Mathew V, Pandit K, Chowdhury S. Primary hyperparathyroidism presenting as recurrent acute pancreatitis: A case report and review of literature. Indian J Endocrinol Metab. $2011 ; 15(1):$ 54-56.

[7] Feder JM, Sirrs S, Anderson D, Sharif J, Khan A. Primary hyperparathyroidism: an overview. International Journal of endocrinology. 2011(2011); 251410. doi:10.1155/2011/25140. Epub 2011 jun 2. 
[8] Shah AA, Shah AV. Parathyroid adenoma in a 2 month old child Indian Pediatrics.2003; 40:1097-98.

[9] Dijkstra B, Healy C, Kelly LM, Mcdermott EW, Hill AD, O'Higgins N. Parathyroid localization- current practice. J R Coll Surg Edinb. 2002; 47: 599-607.
[10] Roejen J, Levine MA. Primary hyperparathyroidism in children and Adolescents. J Chin Med Assoc. 2012; 75(9) :425-34.

\section{AUTHOR(S):}

1. Dr. Chhanda Das

2. Dr. Madhumita Mukhopadhyay

3. Dr. Priyanka Maity

4. Dr. Bedabrata Mukhopadhyay

\section{PARTICULARS OF CONTRIBUTORS:}

1. Assistant Professor, Department of Pathology, IPGME \& R, India.

2. Professor, Department of Pathology, IPGME \& R, India.

3. Postgraduate Student, Department of Pathology, IPGME \& R, India.
4. Postgraduate Student, Department of Biochemistry, IMS, BHU, India.

\section{NAME, ADDRESS, E-MAIL ID OF THE} CORRESPONDING AUTHOR:

Dr. Chanda Das,

31 Eastern Park, First Road, Santoshpur, Kolkata-700075, West Bengal, India.

E-mail: chhhdas@gmail.com

FINANCIAL OR OTHER COMPETING INTERESTS:

None.

Date of Publishing: Apr 01, 2016 